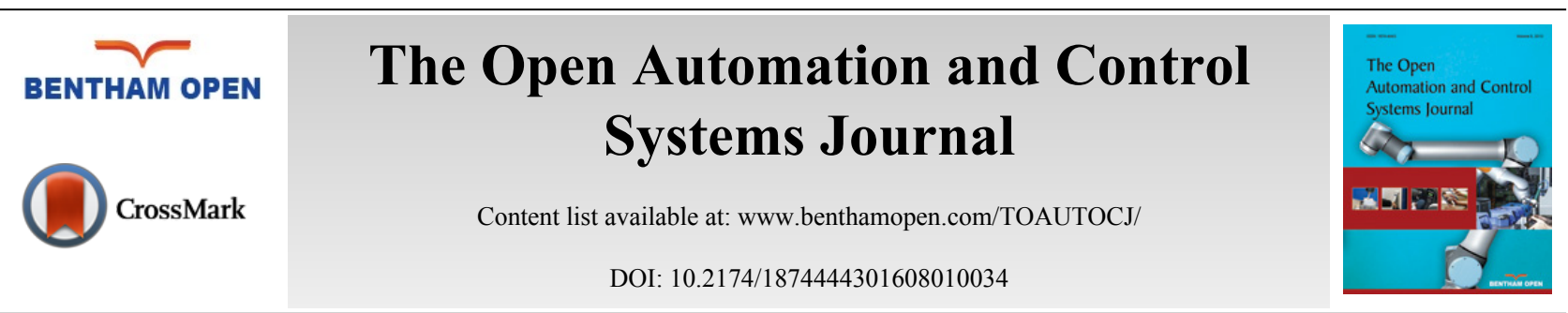

\title{
Retraction Notice: The Function of Achieving the SDN Based on the Ethernet and the Open Flow Network
}

\author{
Min Chen, Jing- guo Zhao, Ze-jun Li and Ang Li \\ School of Computer Science and Technology, Hunan Institute of Technology, Hengyang, China
}

\section{RETRACTION}

The Publisher and Editor have retracted this article [1] in accordance with good ethical practices. It was found plagiarised and similar article was published in other journal [2]. The article was published on-line on 09-10-2015.

\section{REFERENCE}

[1] M. Chen, J.- g. Zhao, Z-j. Li, and A. Li, "The function of achieving the SDN based on the ethernet and the open flow network", Open Autom. Control Syst. J., vol. 7, pp. 1680-1689, 2015.

[2] Y.-W. Lee, "Software defined network based on ethernet-in-core openflow-at- edge network architecture", J. Informat. Commun. Technol., vol. 3, pp. 13-20, 2015.

(c) Chen et al.; Licensee Bentham Open.

This is an open access article licensed under the terms of the Creative Commons Attribution-Non-Commercial 4.0 International Public License (CC BY-NC 4.0) (https://creativecommons.org/licenses/by-nc/4.0/legalcode), which permits unrestricted, non-commercial use, distribution and reproduction in any medium, provided the work is properly cited.

\footnotetext{
* Address correspondence to these authors at Hunan Institute of Technology, Hengyang, China; Tel: +008613875609142; Fax: +0086734-3452076; E-mails: 445283431@qq.com
} 